\title{
sensors
}

ISSN 1424-8220

(C) 2005 by MDPI

http://www.mdpi.org/sensors

\section{Modern Electrochemical Methods for Monitoring of Chemical Carcinogens}

\author{
Jiri Barek $^{1, *}$, Josino Costa Moreira ${ }^{2}$ and Jiri Zima ${ }^{1}$ \\ ${ }^{1}$ UNESCO Laboratory of Environmental Electrochemistry, Department of Analytical Chemistry, \\ Charles University, 12843 Prague 2, Czech Republic \\ 2 CESTEH/ENSP/FIOCRUZ, Rua Leopoldo Bulhoes, 1480 Manguinhos, 21041-210 Rio de Janeiro, \\ Brazil
}

*Author to whom correspondence should be addressed. E-mail: barek@natur.cuni.cz

Received: 15 December 2003 / Accepted: 07 April 2005 / Published: 08 April 2005

\begin{abstract}
This contribution is based on our presentation at the $1^{\text {st }}$ International Symposium on Sensor Science, Paris, 16-20 June 2003. It presents recent results regarding the electrochemical determination of submicromolar and nanomolar concentrations of various carcinogenic substances (nitrated polycyclic aromatic hydrocarbons, heterocyclic compounds, azo compounds, aromatic amino compounds, etc.) using both traditional (classical dropping mercury electrode, static mercury drop electrode, hanging mercury drop electrode) and non-traditional types of electrodes (solid amalgam electrodes, carbon paste electrodes, platinum tubular electrodes).
\end{abstract}

Keywords: mercury electrodes, solid amalgam electrodes, carbon paste electrodes, carcinogens. 


\section{Introduction}

Ethical, social, and economic consequences of various forms of cancer raise carcinogenic substances monitoring in general and working environment to the highest priority [1]. Electrochemical methods are especially suitable for large scale environmental monitoring of chemical carcinogens [2] because they are inexpensive, extremely sensitive and they present an independent alternative to so far prevalent spectrometric and separation techniques.

For batch analysis, modern polarographic and voltammetric techniques such as differential pulse polarography (DPP) and differential pulse voltammetry (DPV) [3] are sensitive enough even for submicromolar concentrations. Adsorptive stripping voltammetry (AdSV) originating from pioneering works [4,5] of Kalvoda enables a fast and sensitive determination of nanomolar and subnanomolar concentrations of electrochemically active substances [2]. For flowing systems, amperometric techniques at suitably arranged electrode systems provide satisfactory sensitivity [6] required for the determination of environmental carcinogens. The most import factor influencing the analytical parameters of polarographic, voltammetric and amperometric determinations is the quality of the electrode, where the electrode material is playing the crucial role. Therefore, our research is oriented on the systematic development of extremely sensitive electrochemical methods suitable for the determination of submicromolar concentrations of various environmental carcinogens using different electrode materials and arrangements.

For electrochemically reducible substances (e.g., nitro, nitroso and azo compounds) we use either mercury electrodes [7] (classical dropping mercury electrode, static mercury drop electrode, hanging mercury drop electrode; suitable for the determination of reducible carcinogens with limits of determination (LOD) down to $10^{-9}$ or $10^{-10} \mathrm{~mol} / \mathrm{L}$ ) or solid amalgam electrodes, which are environmentally friendly alternatives to mercury electrodes suitable both for batch analysis and for HPLC-ED with LOD down to $10^{-7} \mathrm{~mol} / \mathrm{L}$ [8].

For electrochemically oxidizable compounds (such as aromatic amines or phenols) we are employing classical carbon paste electrodes (suitable for the determination of oxidizable carcinogens with LOD down to $10^{-7} \mathrm{~mol} / \mathrm{L}$ [9]) and glassy carbon paste electrodes (compatible with a high content of organic solvent and thus, applicable for HPLC-ED with a high content of organic modifier in a mobile phase with LOD down to $\left.10^{-7} \mathrm{~mol} / \mathrm{L}[10]\right)$.

We pay attention to various possibilities of increasing both the sensitivity and selectivity of these methods using preconcentration of chemical carcinogens on the surface of working electrodes and their preliminary separation and preconcentration using liquid-liquid extraction or solid-phase extraction.

\section{Polarography and voltammetry at mercury electrodes}

Modern polarographic and voltammetric methods, like differential pulse polarography (DPP) at a classical dropping mercury electrode (DME), differential pulse voltammetry (DPV) at a hanging mercury drop electrode (HMDE) or adsorptive stripping voltammetry (AdSV) at a HMDE meet the stringent conditions on sensitivity essential in the determination of biologically active organic 
substances in the environment and in various biological matrices. The usual limits of detection are around $10^{-7} \mathrm{M}$ for DPP at DME, $10^{-8} \mathrm{M}$ for DPV at HMDE and around $10^{-10} \mathrm{M}$ for AdSV at HMDE [7]. Mercury electrodes are up to now the best available sensors for polarographic and voltammetric determination of trace amounts of environmentally important analytes. Their main advantages are:

- Easy renewal of their surface minimizing problems with the passivation,

- extremely broad potential window in cathodic region,

- high sensitivity,

- extremely broad concentration range from $10^{-3}$ to $10^{-10} \mathrm{M}$,

- broad spectrum of analytes (organic, inorganic, organometallic, macromolecular substances, etc.),

- low investment and running costs,

- high speed,

- molecule of an analyte is a direct source of signal,

- they present an independent alternative to spectrometric and separation methods (this is important from legal point of view because the "proof beyond reasonable doubt" requires several independent methods).

Their main disadvantage (lower selectivity and more demanding personal requirements) can be overcome by their combination with a suitable preliminary separation and by careful training of laboratory personnel.

There are several types of mercury electrodes, each of them having their own advantages and disadvantages:

Classical DME is nowadays used mostly for the investigation of the mechanism of electrochemical reactions; however, it can play a very useful role in combination with DPP for the analysis of waste waters, biological fluids and other matrices containing substances causing the passivation of the working electrode. In those cases, a periodical renewable surface of the DME can eliminate problems connected with the passivation.

HMDE is the most frequently used electrode today for analytical purposes. Its main advantage is the possibility of accumulation of the analyte on its surface as in the case of anodic striping voltammetry (ASV) or AdSV and a lower consumption of mercury. However, it is more prone to passivation problems because its surface is not renewed during the recording of the polarization curve.

SMDE (static mercury drop electrode) is more resistant towards passivation problems because its surface is periodically renewed during the measurement and provides a lower limit of detection because of lower charging current connected with the constant surface of the electrode during the current sampling period.

MFE (mercury film electrode) is particularly suitable for anodic stripping voltammetric (ASV) determination of trace metals as it provides sharper and higher ASV peaks because of shorter diffusion time needed for metals to get through thin film as compared with relatively bulky mercury drop [11]. Moreover, micro MFE can be easily prepared [12]. 
Step-wise growing mercury drop or shrinking mercury drop [13] and miniaturized and contractible (compressible) mercury electrodes offer new possibilities in voltammetry of biologically active species [14].

A number of methods for the determination of various chemical carcinogens (e.g. nitrated polycyclic aromatic hydrocarbons, N-nitroso compounds, azo compounds, triazenes, etc.) were developed in our UNESCO Laboratory of Environmental Electrochemistry. The complete list of the methods developed prior 1995 can be found in review [15], where optimum techniques, conditions, concentration ranges and limits of determination are summarized for the determination of twelve genotoxic derivatives of N,N-dimethyl-4-aminoazobenzene (unsubstituted compound, its 3'-halogen, 3'-methyl, 3'-nitro, 4'-amino and 4'-halogen derivatives), of seven 4-substituted derivatives of N-nitroso-N-methylaniline $\left(\mathrm{R}=\mathrm{H}, \mathrm{CH}_{3}, \mathrm{OCH}_{3}, \mathrm{Cl}, \mathrm{CN}, \mathrm{OH}\right.$ and $\left.\mathrm{NO}_{2}\right)$, of six derivatives of 1-phenyl-3,3-dimethyltriazene (aromatic ring substituted with 2'-, 3'- and 4'- $\mathrm{CONH}_{2}, 2^{\prime}-\mathrm{NO}_{2}, 4^{\prime}-\mathrm{C}_{6} \mathrm{H}_{4}{ }^{-}$ $\mathrm{N}=\mathrm{N}-$ and $4^{\prime}-\mathrm{Br}$ ), and of three heterocyclic hydrocarbons (acridine, benz[c]acridine and dibenz[a,h]acridine). The mechanism of polarographic reduction of the above-mentioned substances on mercury electrodes is described in this review as well.

Similarly, polarographic and voltammetric methods developed in our laboratory until 2000 for the determination of submicromolar concentrations of carcinogenic nitrated polycyclic aromatic hydrocarbons (namely 1-nitropyrene, 9-nitroanthracene, 2-nitrofluorene and 2,7-dinitrofluorene (see ref. [16,17]) and 4-nitrobiphenyl, 1-nitro-naphthalene and 6-nitro-chrysene (see ref. [1]) and their applications for environmental samples were published.

Some selected applications of recently developed methods are summarized in Table 1. The selectivity and sensitivity of most such determination can be substantially increased by a suitable preliminary separation and preconcentration method. Genotoxic 1-nitronaphthalene can be determined using preliminary solid-phase extraction (SPE) on Lichrolut RP Select B columns (Merck) by DPV at HMDE in the concentration range of $(2-10) * 10^{-9} \mathrm{M}$ and $(2-10)^{*} 10^{-8} \mathrm{M}$ drinking and river water, respectively [18]. Similarly, liquid-liquid extraction (LLE) of 2-nitronaphthalene by hexane followed by DPV at HMDE enables its determination in the concentration range of $(2-10) * 10^{-10} \mathrm{M}$ in drinking water [18]. Preliminary separation and preconcentration of 6-methyl-5-nitroquinoline, 6-methyl-5nitrouracil, and 8-nitro-quinoline using SPE or LLE enables their polarographic or voltammetric determination on DME or HMDE in submicromolar concentration ranges in drinking and river waters (see refs. in Table 1). For the sake of illustration, selected DP voltammograms of 6-methyl-5nitrouracil are depicted in Fig. 1.

It is obvious that mercury is the best electrode material for the polarographic and voltammetric determination of electrochemically reducible pollutants. However, because of fears of mercury toxicity (although irrational and unsubstantiated according to our opinion), there is a tendency to substitute mercury with other non-toxic materials. For that reason, new types of metal-solid amalgam electrodes were introduced $[8,17]$. Their typical representative is the practically non-toxic mercury meniscusmodified silver-solid amalgam electrode (m-AgSAE), which has a good mechanical stability, simple handling and regeneration including an electrochemical pre-treatment of its surface, etc. The electrode consists of a drawn-out glass tube, the bore of which near the tip is filled with a fine silver powder, 
amalgamated by liquid mercury and connected to an electric contact. Afterwards, it is immersed into a small volume of liquid mercury and agitated for 15 seconds.

Table 1. Selected examples of recently developed methods of polarographic and voltammetric determination of chemical carcinogens.

\begin{tabular}{|c|c|c|c|c|c|}
\hline Substance & Technique & Electrode & Medium & LOD, M & Ref. \\
\hline \multicolumn{6}{|c|}{ Nitrated polycyclic aromatic hydrocarbons } \\
\hline \multirow[t]{4}{*}{ 1-nitronaphthalene } & DPP & DME & $\begin{array}{l}0.01 \mathrm{M} \mathrm{NaOH} \\
-\mathrm{MeOH}(1: 1), \mathrm{pH} 12.2\end{array}$ & $1.10^{-7}$ & 18 \\
\hline & DPV & HMDE & $\begin{array}{l}0.01 \mathrm{M} \mathrm{NaOH} \\
\text {-MeOH (9:1), pH } 12.0\end{array}$ & $3.10^{-8}$ & \\
\hline & AdSV & HMDE & $0.001 \mathrm{M} \mathrm{LiOH}$ & $2.10^{-9}$ & \\
\hline & DPV & AgSAE & $\begin{array}{l}\text { BR-MeOH } \\
(9: 1), \mathrm{pH} 7\end{array}$ & $3.10^{-7}$ & 18 \\
\hline \multirow[t]{4}{*}{ 3-nitrobiphenyl } & DPP & SMDE & BR-MeOH (1:1), pH 12 & $3.10^{-8}$ & 19 \\
\hline & DPV & HMDE & BR-MeOH (1:1), pH 12 & $2.10^{-8}$ & \\
\hline & AdSV & HMDE & $\begin{array}{l}0.01 \mathrm{M} \mathrm{NaOH}-\mathrm{MeOH} \\
(100: 1), \mathrm{pH} 12\end{array}$ & $2.10^{-9}$ & \\
\hline & DPV & AgSAE & $0.2 \mathrm{M} \mathrm{NaOH}-\mathrm{MeOH}(1: 1)$ & $3.10^{-7}$ & 22 \\
\hline \multicolumn{6}{|c|}{ Heterocyclic aromatic hydrocarbons } \\
\hline \multirow[t]{3}{*}{ 8-nitroquinoline } & DPP & DME & BR-MeOH (9:1), pH 5 & $1.10^{-7}$ & 20 \\
\hline & DPV & HMDE & BR-MeOH (1:1), pH 4 & $2.10^{-8}$ & \\
\hline & AdSV & HMDE & 0.002 M LiOH-MeOH $(9: 1)$ & $2.10^{-8}$ & \\
\hline \multirow{3}{*}{$\begin{array}{l}\text { 6-methyl-5- } \\
\text { nitroquinoline }\end{array}$} & DPP & DME & BR-MeOH (1:1), pH 5 & & 21 \\
\hline & DPV & HMDE & BR-MeOH(1:1), pH 6 & & \\
\hline & AdSV & HMDE & $0.01 \mathrm{M} \mathrm{NaOH}-\mathrm{MeOH}(99: 1)$ & $2.10^{-8}$ & \\
\hline \multirow[t]{2}{*}{ 6-methyl-5-nitrouracil } & DPP & DME & $\mathrm{BR}, \mathrm{pH} 6$ & $2.10^{-7}$ & 21 \\
\hline & DPV & HMDE & $\mathrm{BR}, \mathrm{pH} 7$ & $2.10^{-7}$ & \\
\hline
\end{tabular}

BR-Briton-Robinson buffer, $\mathrm{MeOH}$ - methanol, LOD - limit of detection 


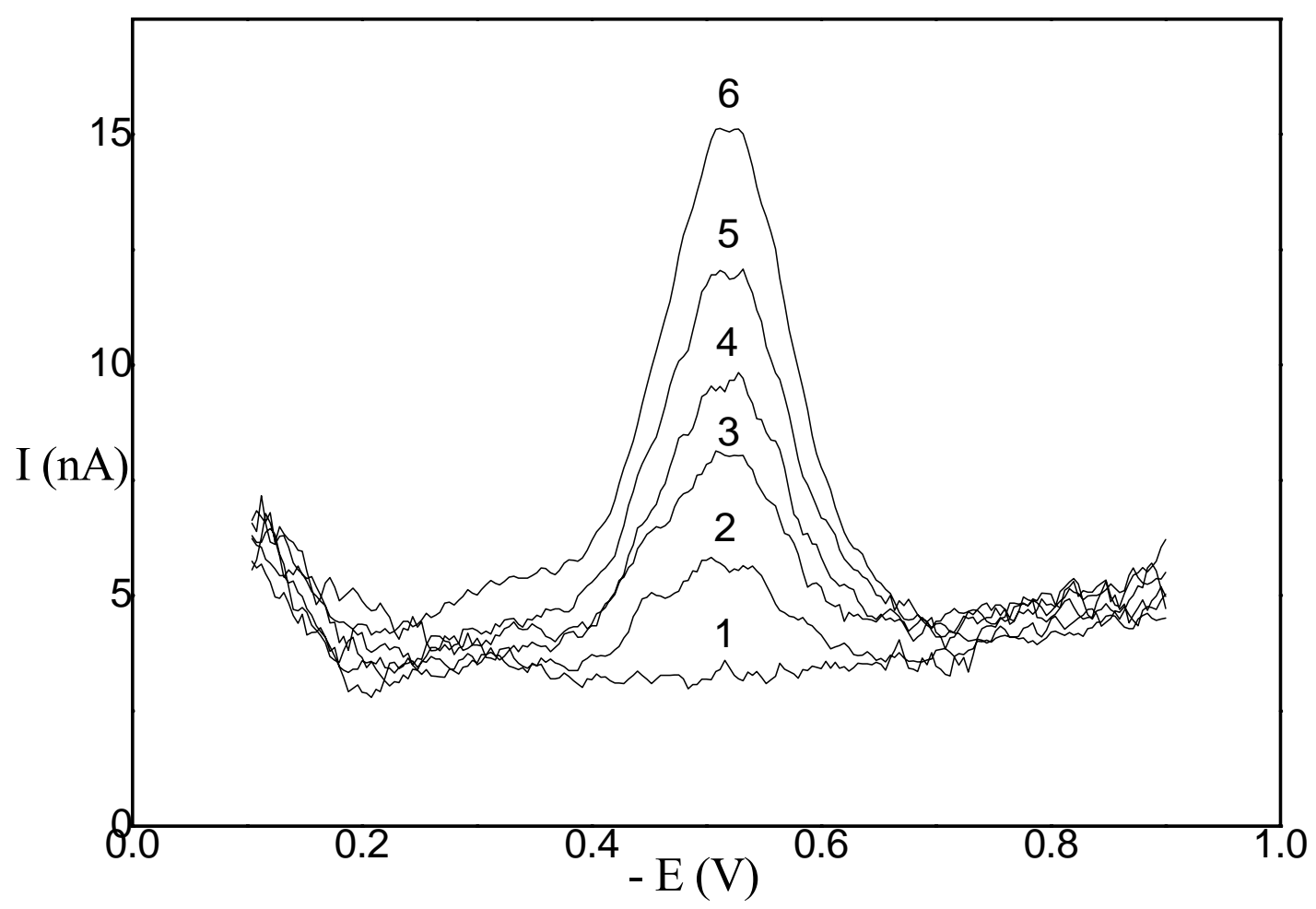

Figure 1. DP voltammograms on HMDE of 6-methyl-5-nitrouracil in Britton-Robinson buffer, $\mathrm{pH} 7.0$ at concentrations $0(1), 2 * 10^{-7}(2), 4^{*} 10^{-7}(3), 6^{*} 10^{-7}(4), 8^{*} 10^{-7}(5)$, and $10^{*} 10^{-7}(6) \mathrm{mol}^{-1}$.

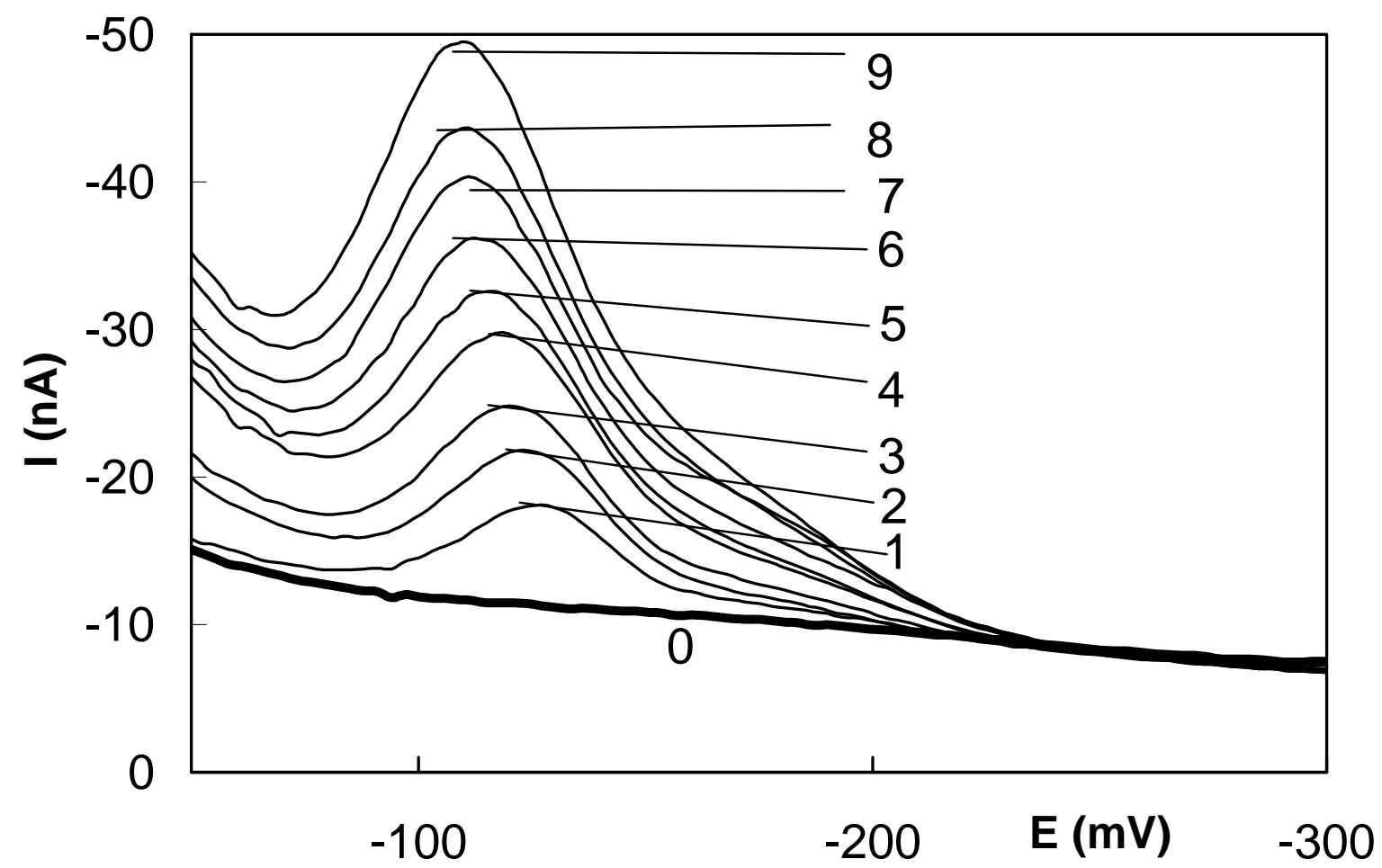

Figure 2. Differential pulse voltammograms of N,N-dimethyl-4-amino-2'-carboxy-azobenzene at m-

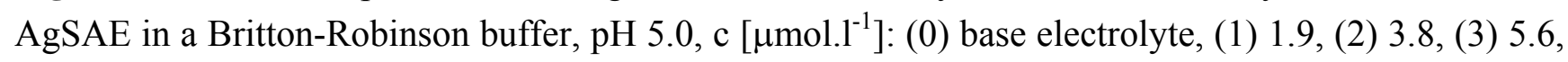
(4) 7.4, (5) 9.0, (6) 10.7, (7) 12.2, (8) 13.7, (9) 15.2. 
Before starting the work as well as after every pause longer than one hour, the electrochemical activation of $\mathrm{m}-\mathrm{AgSAE}$ should be carried out in $0.2 \mathrm{M} \mathrm{KCl}$ at $-200 \mathrm{mV}$ under stirring of the solution for 300 seconds followed by rinsing with distilled water. The m-AgSAE could be used for several weeks without major changes, only its regeneration through mechanical contact with mercury is recommended to be repeated every week. In absence of specific interactions between the analyte and silver the DPV peak potentials on m-AgSAE and hanging mercury drop electrode (HMDE) are nearly the same. This electrode was found suitable for the determination of submicromolar concentrations of selected nitrated polycyclic aromatic hydrocarbons, which are typical representatives of polarographically active environmental carcinogens [22] and for the determination of selected genotoxic azo dyes [23] (see Table 1). For the sake of illustration, DP voltammograms of N,Ndimethyl-4-amino-2' -carboxyazobenzene at AgSAE are depicted in Fig. 2.

\section{Voltammetry at carbon paste electrodes}

In 1958, shortly before Professor Heyrovský received the Nobel Prize, Adams reported on a new type of electrode [24] formed by a mixture of carbon powder with a liquid non-electroactive binder and called simply "carbon paste". The original idea was to develop a "dropping carbon electrode" constructed similarly like the DME, i.e. from a reservoir with suspension of carbon powder in a liquid and connected to a capillary, allowing one to obtain periodically renewable droplets of this "carbon electrode" as a certain analogy to the DME for anodic oxidations of organic compounds. Although practical experiments with the carbon dropping electrode failed, the above-mentioned mixture of carbon powder and a binder prepared in thicker consistency proved to be a very useful electrode material [9]. In our laboratory carbon paste electrodes are frequently used for the determination of micromolar concentrations of aromatic amines and other electrochemically oxidizable chemical carcinogens. The voltammetric determination of 2-aminofluorene and 2,7-di-aminofluorene based on their oxidation on carbon paste electrode can serve as an example [25]. Britton-Robinson buffer and $\mathrm{pH}$ ranges 1-3 and 10-12 are recommended for the simultaneous determination of these two carcinogenic amines. The sensitivity of the determination can be enhanced substantially by an adsorptive accumulation of analytes on the carbon paste electrode in the $\mathrm{pH}$ range 10-12. The detection limits for the accumulation time $200 \mathrm{~s}$ are around $2 * 10^{-7}$ and $1 * 10^{-7} \mathrm{M}$ for 2-aminofluorene and 2,7diaminofluorene, respectively. Relative standard deviations for the concentration range $(1-10)^{*} 10^{-7} \mathrm{M}$ does not exceed $10 \%$. Carbon paste electrodes modified with monomeric $\alpha$-, $\beta$ - or $\gamma$-cyclodextrin and carbon-based screen-printed electrodes surface-modified with a thin film of $\beta$-cyclodextrin or carboxymethylated $\beta$-cyclodextrin condensation polymer were used for the voltammetric determination of carcinogenic amino derivatives of polycyclic aromatic hydrocarbons, namely 1- and 2-amino-naphthalene and 2-aminobiphenyl. Linear calibration curves within the concentration range of $2 * 10^{-8}-2 * 10^{-6} \mathrm{M}$ were obtained for the modified CPE and modified screen-printed electrode [26]. Another interesting possibility is the application of a carbon paste electrode based on glassy carbon microbeads for the determination of micromolar concentrations of genotoxic amino and nitro derivatives of pyrene [27]. The main advantage of this type of electrode, originally proposed by Vytras 
[28] and Wang [29], is its compatibility with a high content of organic solvents (up to $90 \%$ of methanol) which otherwise prevents the application of carbon paste electrodes.

\section{HPLC with electrochemical detection (ED)}

This technique combines the high separation power of HPLC with an extreme sensitivity of modern electroanalytical methods and thus, can be a very valuable tool in environmental analysis [30]. This fact can be demonstrated by the following three examples from our laboratory:

- Application of platinum tubular detector developed in our laboratory [31] for the determination of trace amounts of carcinogenic aromatic amines and its metabolites. This very simple device was used for HPLC ED determination of submicromolar concentrations of 1- and 2-aminonaphthalene [32], 1-,2-, 3- and 4-hydroxyphenanthrene [33,] 3-, 5-, 6-, and 8-aminoquinoline [34], and 2- and 4aminobiphenyl and 2- and 4-hydroxybiphenyl [35].

- Application of a carbon paste electrode based on glassy carbon micro beads for HPLC determination of genotoxic pyrene derivatives, namely 1-aminopyrene and 1-hydroxypyrene [27]. This type of working electrode in a wall-jet arrangement is compatible with a relatively high content of an organic solvent (methanol, acetonitrile, etc.) in a mobile phase.

- Application of AgSAE for rather selective HPLC ED determination of polarographically active organic substances [36]. In this case, AgSAE serves as a working electrode in a wall-jet arrangement (see Fig. 3). LOD is around $10^{-6} \mathrm{M}$, i.e. comparable with HMDE working electrode. However, AgSAE is mechanically much more stable then HMDE.

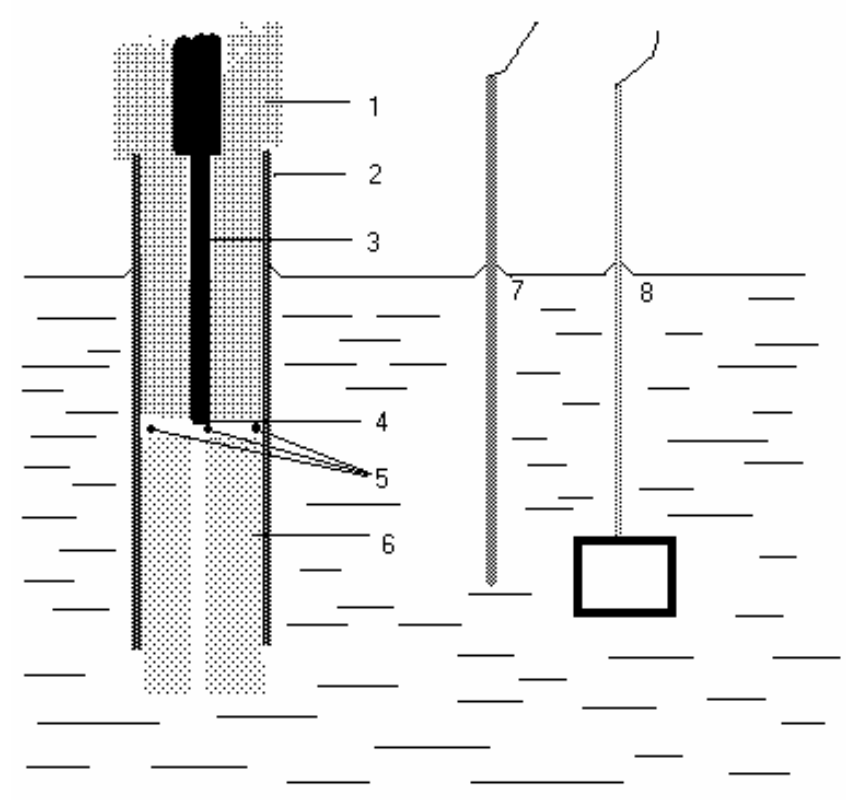

Figure 3. Scheme of HPLC detector with AgSAE electrode: 1) glass, 2) plastic tube, 3) silver amalgam, 4) mercury meniscus, 5) holes, 6) Teflon tube-outlet of HPLC, 7) reference electrode, 8) auxiliary electrode. 


\section{Acknowledgements}

This research was supported by the Grant Agency of the Czech Republic (grant no. 203/03/0182).

\section{References and notes}

1. Barek, J.; Cvačka, J.; Muck, A.; Quaiserová, V.; Zima, J. Electrochemical methods for monitoring of environmental carcinogens, Fresenius J. Anal. Chem. 2001, 369, 556.

2. Barek, J.; Cvačka, J.; Muck, A.; Quaiserová, V.; Zima, J. Polarographic and voltammetric determination of carcinogenic nitro and amino derivatives of polycyclic aromatic hydrocarbons, Electroanalysis 2001, 13, 799.

3. Kalvoda, R. Instrumentation in analytical chemistry; Ed.: Zýka, J., Ed.; Horwood: London, 1994, p. 54.

4. Kalvoda, R. Adsorptive accumulation in stripping voltammetry, Anal. Chim. Acta 1982, 138, 11.

5. Kalvoda, R. Adsorptive stripping voltammetry of electroactive organic compounds, Anal. Chim. Acta 1984, 162, 197.

6. Štulík, K.; Pacáková, V. In: Instrumentation in analytical chemistry, Vol. 1; Ed.: Zýka, J.; Ellis Horwood: Chichester, 1991, p. 84.

7. Barek, J.; Fogg, A.G.; Muck, A.; Zima, J. Polarography and voltammetry at mercury electrodes, Crit. Rev. Anal. Chem. 2001, 31, 291.

8. Yosypchuk, B.; Novotný, L. Nontoxic electrodes of solid amalgams, Crit. Rev. Anal. Chem. 2002, 32, 141.

9. Švancara, I.; Vytřas, K.; Barek, J.; Zima, J. Carbon paste electrodes in modern electroanalysis, Crit. Rev. Anal. Chem. 2001, 31, 311.

10. Barek, J.; Muck, A.; Wang, J.; Zima, J. Study of voltammetric determination of carcinogenic 1nitropyrene and 1-aminopyrene using a glassy carbon paste electrode, Sensors 2004, $4,47$.

11. Economou, A.; Fielden, P.R. Applications, potentialities and limitations of adsorptive stripping analysis on mercury film electrodes, Trends Anal. Chem. 1997, 16, 286.

12. Emons, H.; Baade, A.; Schöning, M.J. Voltammetric determination of heavy metals in microvolumes of rain water, Electroanalysis 2000, 12, 1171.

13. Novotný, L. Compression of the interfacial boundary electrode-solution as the basis of new compression accumulation (stripping) techniques, Electroanalysis 1996, 8, 135.

14. Novotný, L. Voltammetry of biologically active species and surfactants on new miniaturized and contractible (compressible) mercury electrodes, Fresenius J. Anal. Chem. 1999, 363, 55. 
15. Barek, J.; Zima, J. Electrochemistry of environmentally important organic substances In Electrochemistry for environmental protection Eds.: Štulík, K.; Kalvoda, R.; UNESCO Technical Report No. 25. UNESCO Regional Office for Science and Technology for Europe (ROSTE), Venice 1996, 137.

16. Barek, J.; Pumera, M.; Muck, A.; Kadeřábková, M.; Zima, J. Polarographic and voltammetric determination of selected nitrated polycyclic aromatic hydrocarbons, Anal. Chim. Acta 1999, 393, 141.

17. Yosypchuk, B.; Novotný, L. Solid amalgam electrodes. US-CZ Workshop on Electrochemical Sensors; Eds.: Barek, J.; Drašar, P. Czech Chemical Society, Prague 2001, 26.

18. Pecková, K. Diploma Thesis, Charles University, Faculty of Science, Prague 2001.

19. Štěpán, R. Diploma Thesis, Charles University, Faculty of Science, Prague 2001.

20. Kolářová, J. Diploma Thesis, Charles University, Faculty of Science, Prague 2002.

21. Fantová, N. Diploma Thesis, Charles University, Faculty of Science, Prague 2001.

22. Pecková, K.; Barek, J.; Dřevínek, M.; Navrátil, T.; Novotný, L.; Yosypchuk, B.; Vaingatová, S.; Zima, J. Determination of nitrated polycyclic aromatic hydrocarbons using a solid-silver amalgam electrode. US-CZ Workshop on Electrochemical Sensors; Eds.: Barek, J.; Drašar, P.; Czech Chemical Society, Prague 2001, 32.

23. Barek, J.; Dodova, E.; Navrátil, T.; Yosypchuk, B.; Novotný, L.; Zima, J. Voltammetric determination of N,N-dimethyl-4-aminocarboxyazobenzene at a silver solid amalgam electrode, Electroanalysis 2003, 15, 1778.

24. Adams, R.N. Carbon paste electrodes, Anal. Chem. 1958, 30, 1576.

25. Armalis, S.; Novikova, N.; Kubiliene, E.; Zima, J.; Barek, J. Voltammetric determination of 2aminofluorene and 2,7-diaminofluorene using carbon paste electrode, Anal. Lett. 2002, 32, 1551.

26. Ferancová, A.; Korgová, E.; Labuda, J.; Zima, J.; Barek, J. Cyclodextrin modified carbon paste based electrodes as sensors for the determination of carcinogenic polycyclic aromatic amines, Electroanalysis 2002, 14, 1668.

27. Muck, A. PhD Thesis, Charles University, Faculty of Science, Prague 2002.

28. Svancara, I.; Hvizdalova, M.; Vytras, K.; Kalcher, K.; Novotny, R. A microscopic study on carbon paste electrodes, Electroanalysis 1996, 8, 61.

29. Wang, J.; Kirgoz, U.A.; Mo, J.W.; Lu, J.M.; Kawde, A.N.; Muck, A. Glassy carbon paste electrodes, Electrochem. Commun. 2001, 3, 203.

30. Štulík, K.; Pacáková, V. Electroanalytical measurements in flowing liquids. E. Horwood: Chichester, 1987. 
31. Cvačka, J.; Opekar, F.; Barek, J.; Zima, J. An amperometric detector with a platinum tubular electrode for high performance liquid chromatography, Electroanalysis, 2000, 12, 39.

32. Quaiserová, V. Diploma Thesis, Charles University, Faculty of Science, Prague 2000.

33. Smutná, K. Diploma Thesis, Charles University, Faculty of Science, Prague 2001.

34. Hříbal, Z. Diploma Thesis, Charles University, Faculty of Science, Prague 2001.

35. Vaingátová, S. Diploma Thesis, Charles University, Faculty of Science, Prague 2002.

36. Pastor, F.; Barek, J.; Novotný, L.; Yosypchuk, B.; Zima, J.; Navrátil, T. unpublished results.

C 2005 by MDPI (http://www.mdpi.net). Reproduction is permitted for non-commercial purposes. 